\title{
Preoperative Trans-Arterial Embolization and Surgical Resection for Giant Liver Hemangioma: A Multidisciplinary Approach
}

\author{
Andrew D Tieniber ${ }^{1}$, Mihir M Shah ${ }^{2}$, Oliver S Eng ${ }^{3}$, John L Nosher ${ }^{4}$ and Darren R Carpizo ${ }^{2 *}$ \\ ${ }^{1}$ Rutgers Robert Wood Johnson Medical School, New Brunswick, NJ \\ ${ }^{2}$ Division of Surgical Oncology, Rutgers Cancer Institute of New Jersey, New Brunswick, NJ \\ ${ }^{3}$ Department of Surgery, City of Hope National Medical Center, Duarte, CA \\ ${ }^{4}$ Department of Radiology, Robert Wood Johnson University Hospital
}

Received: October 09, 2017; Accepted: December 22, 2017; Published: December 27, 2017

*Corresponding author: Darren R Carpizo, Associate Professor of Surgery and Pharmacology, RUTGERS Cancer Institute of New Jersey, RUTGERS Robert Wood-Johnson University Medical School, 195 Little Albany St. Room 3040, New Brunswick, NJ 08903, USA, Tel: 732-235-8524; Fax: 732-235-8098; E-mail: carpizdr@cinj.rutgers.edu

\begin{abstract}
A 47-year-old male presenting with abdominal distension and pain was found to have a giant hemangioma of the liver measuring $22 \mathrm{~cm}$ in its greatest diameter upon preoperative MRI. The patient underwent preoperative trans-arterial embolization (TAE) of the hemangioma, followed by extended right hepatectomy for definitive treatment. This case illustrates a novel multidisciplinary approach to the treatment of a massive liver hemangioma. We propose a new classification of these $>20 \mathrm{~cm}$ hemangiomas that require preoperative TAE as "Super Hemangiomas."
\end{abstract}

\section{Introduction}

Hemangiomas are the most common benign liver tumors and the second most common overall, with a prevalence of 0.4$7.3 \%$ found at autopsy, although other studies have suggested the prevalence of clinically relevant hemangiomas is $0.7-1.5 \%$ [13]. Liver hemangiomas can be characterized as normal or giant based on diameter, although there is no consensus regarding classification. This is reflected in the current literature, with variable definitions of "giant" ranging from upwards of 4 to $10 \mathrm{~cm}$ in diameter [4 -10].

Most hemangiomas are asymptomatic, found incidentally, and remain stable. In a large retrospective cross sectional study, Mocchegiani et al. reported that in patients with hepatic hemangiomas (size $67.3 \pm 20.3 \mathrm{~mm}$ ) with long term follow-up (mean $76.6 \pm 23.8$ months), $75.6 \%$ remained stable in size [11]. Notably, in their group of 910 patients with hemangiomas < 4 $\mathrm{cm}$, all remained asymptomatic. However, patients may present with symptoms due to the hemangioma in $11 \%$ of cases, with abdominal pain being the most common [12]. Complications from hemangiomas include hemorrhage, compression of adjacent organs, or spontaneous rupture, which may develop in hemangiomas $>4 \mathrm{~cm}$ in $3.2 \%$ of cases $[11,13,14]$. Although traditionally treated with surgical resection or enucleation alone, recent treatment modalities include trans-arterial embolization (TAE), radiotherapy, radiofrequency ablation, transplant, chemotherapy, or multi-modal therapy [13]. Trans-arterial embolization has been proposed as a treatment option in giant symptomatic hemangiomas, both alone and in combination with resection [15-23].

We present a patient with a $22 \mathrm{~cm}$ giant hemangioma of the liver treated with preoperative trans-arterial embolization, and surgical resection the following day. This multidisciplinary approach was chosen in an attempt to mitigate potential blood loss and facilitate ease of hepatic transection. This case report is one of few demonstrating this approach in a giant liver hemangioma.

\section{Case Report}

A 47-year-old male presented to his primary care physician with abdominal distension and pain. A CT demonstrated a $22 \mathrm{~cm}$ giant hemangioma of the liver (Figure 1-2). He was subsequently referred to Rutgers Cancer Institute of New Jersey for further evaluation. Due to the size of the hemangioma and anatomical location, resection with pre-operative trans-arterial embolization was considered to be his best treatment option.

One day prior to surgical resection, the patient underwent trans-arterial embolization of the hemangioma. After proper arteriograms of the liver were obtained (Figures 3-5), branches 1-4 of the right hepatic artery were embolized with 45-150 um polyvinyl alcohol particles (PVA) without complication.

An extended right hepatectomy including cholecystectomy and intraoperative ultrasound of the liver was performed. 


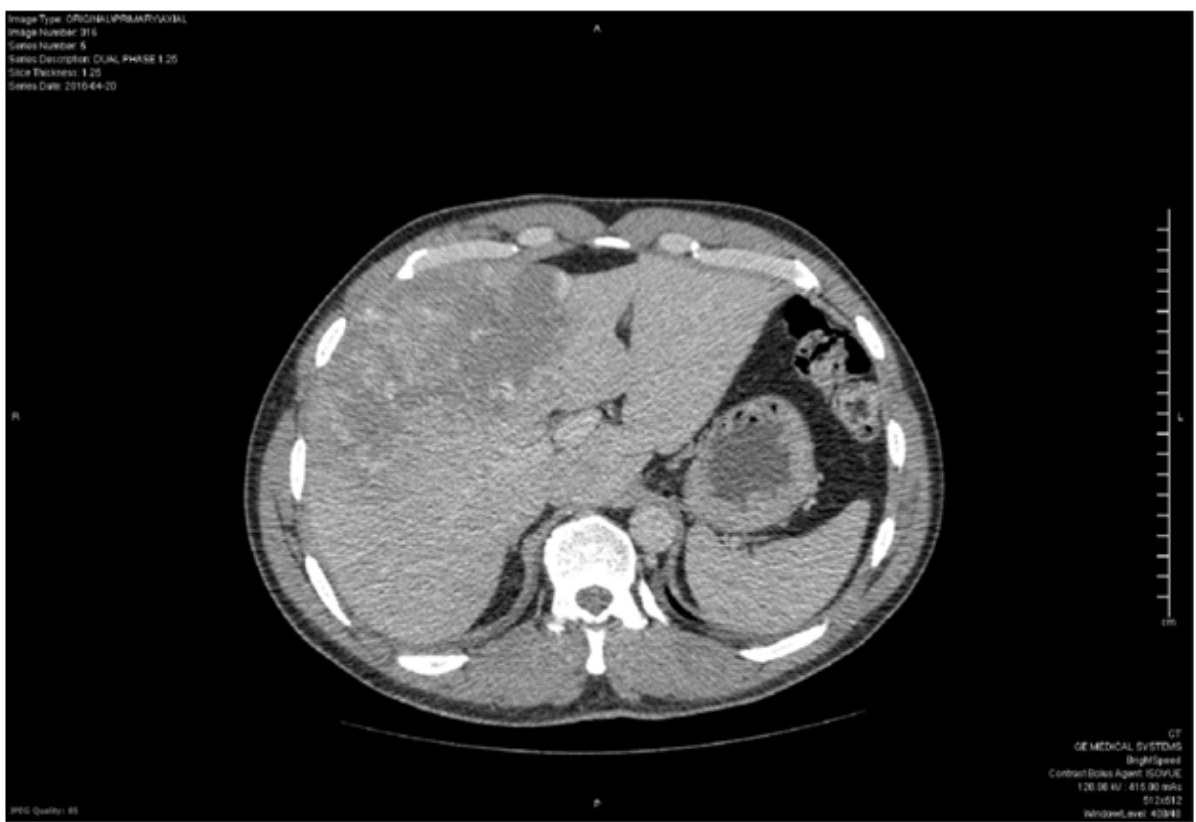

Figure 1: Axial image from CT scan with contrast prior to embolization demonstrating the cranial edge of the hemangioma located in the anterior sector of the right liver extending into segment 4

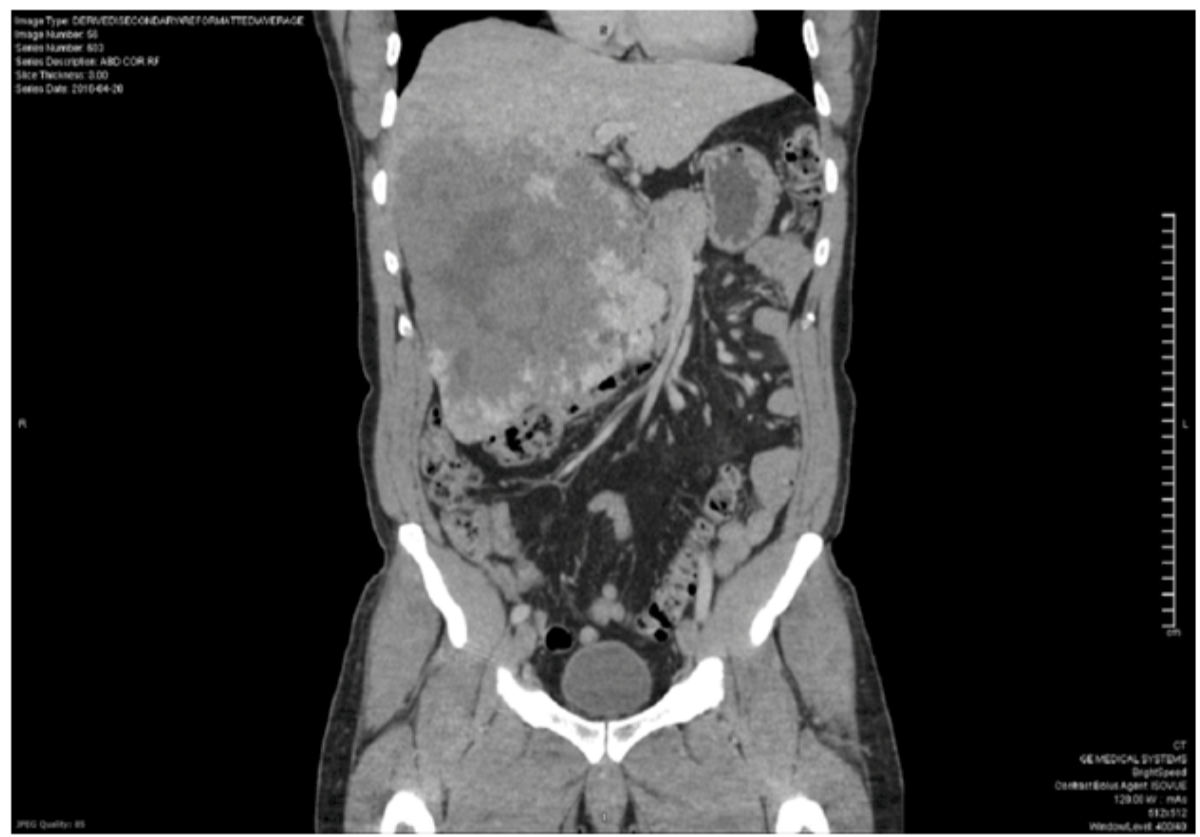

Figure 2: Coronal image from a pre-embolization CT scan with contrast demonstrating the full cranial-caudal extent of the hemangioma. Note the bulk of the lesion growing exophytically inferiorly in the abdomen displacing the duodenum, head of pancreas and mesenteric vessels

Upon inspection of the abdomen, the large hemangioma was anteriorly located within the liver and displacing the colon and intra-abdominal organs inferiorly. The hemangioma appeared ischemic, consistent with the embolization the day prior. The left liver had no palpable lesions, but had hypertrophied in response to the large hemangioma.

The liver was partially mobilized by taking down the falciform 


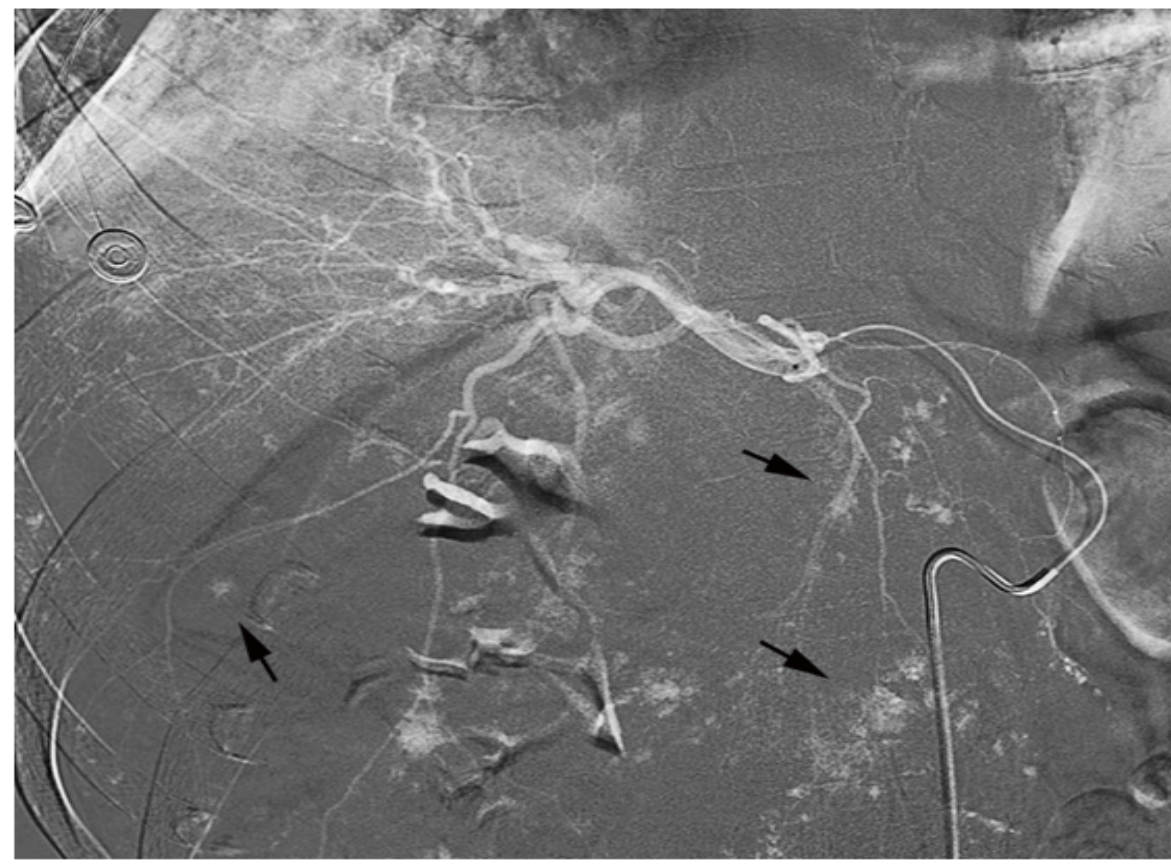

Figure 3: Selective arteriogram of the right hepatic artery demonstrating focal accumulation of contrast in abnormal vascular spaces (arrows)

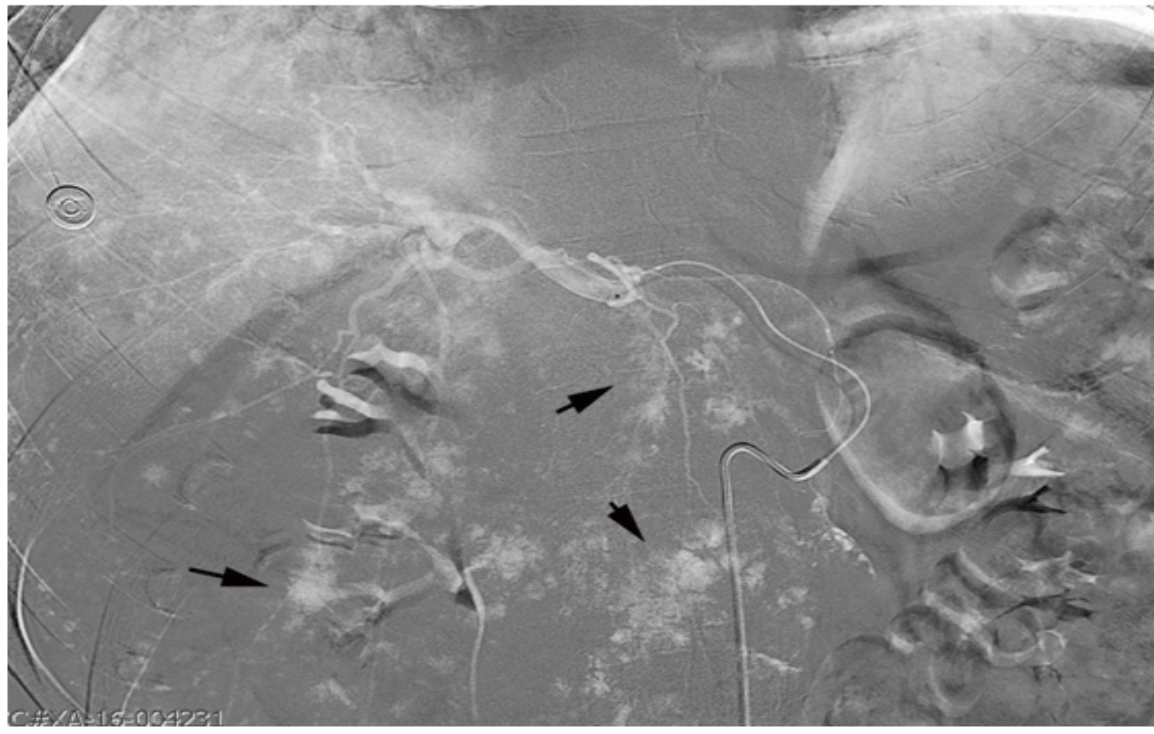

Figure 4: Selective arteriogram of the right hepatic artery demonstrating focal accumulation of contrast in abnormal vascular spaces (arrows)

ligament and the left triangular ligament. And intraoperative ultrasound of the liver revealed no other evidence of intrahepatic lesions. The right liver was mobilized from its retroperitoneal and diaphragmatic attachments. The hemangioma occupied all of segments 4,6 , and 8 , and there was a portion that extended across Cantlie's line into segment 4B. Most of segment 4A was spared, as well as segment 7 . The small venous branches of the caudate lobe were ligated to the level of the inferior vena cava. The vena caval ligament was taken down with a vascular stapler. Due to limited exposure of the right hepatic vein, it was decided to take the right hepatic vein from inside the liver. The porta hepatis was dissected, and a cholecystectomy was performed. The right hepatic artery dissected and ligated, and a bulldog clamp was placed on the right portal vein. 


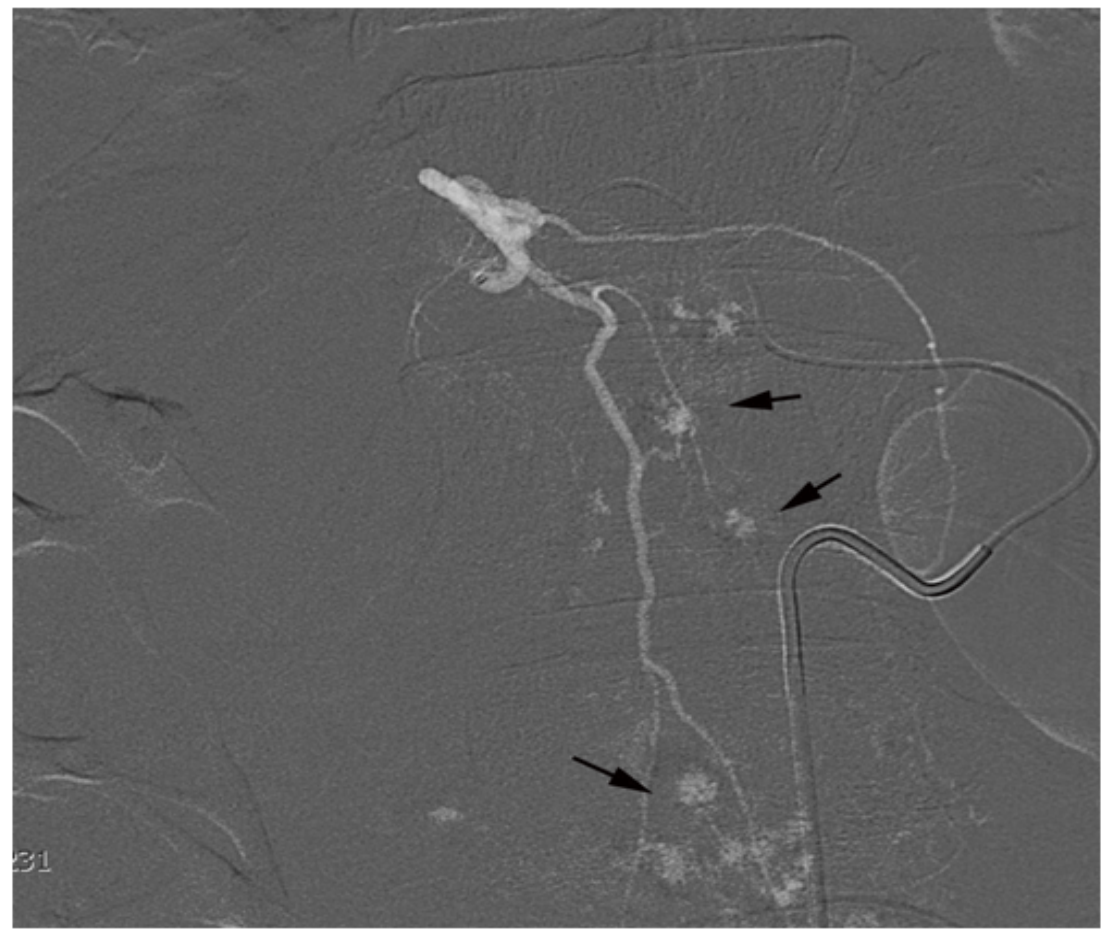

Figure 5: Selective arteriogram of accessory right hepatic artery demonstrating focal accumulation of contrast in abnormal vascular spaces (arrows)

We performed the parenchymal transection using a clampcrush technique. Intra-hepatic vessels were sealed with a vessel sealing device (Ligasure) and smaller blood vessels were controlled with Aquamantysbipolar cautery device. The main right pedicle as well as the remaining hepatic parenchyma was divided with a vascular stapler. Once the specimen was removed (Figure 6), hemostasis was maintained. There were no complications during the operation, and the estimated blood loss was $750 \mathrm{~mL}$. The patient was discharged on postoperative day 7 after an unremarkable postoperative course.

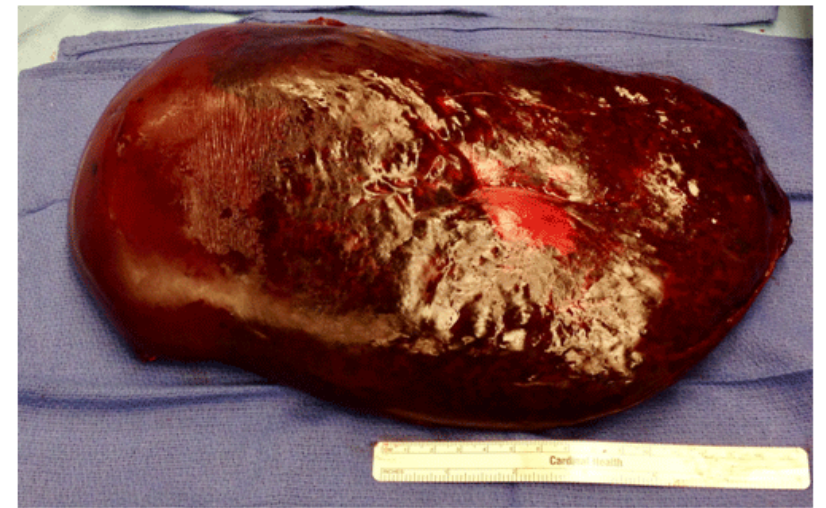

Figure 6: Post-resection specimen indicating the extent of the liver that was occupied by hemangioma and the significant reduction in size by the preoperative embolization

\section{Discussion}

The management of liver hemangiomas can vary from observation to surgical resection, enucleation, trans-arterial ablation, radiotherapy, radiofrequency ablation, transplant, chemotherapy, or multi-modal therapy [13]. In our opinion, several patient factors that influence the outcome of the treatment of a massive liver hemangioma include: liver disease, prior liver surgery, co-morbidities, functional status and compliance. According to the American College of Gastroenterology, treatment can be considered when the hemangioma is $>10 \mathrm{~cm}$ in size, with symptomatic compression of organs or vessels, or with pain or impaired quality of life [14]. Clinically relevant symptoms include abdominal pain, nausea, vomiting, dyspepsia, early satiety, jaundice, and weight gain, with pain being the most common symptom due to liver capsule distension [24, 25]. One study reported that $50 \%$ of patients found to have a liver hemangioma were referred due to abdominal pain, although only $12.6 \%$ of those patients had pain attributable to the hemangioma itself [26]. Thus, it is important to investigate patients for comorbidities such as peptic ulcer disease or inflammatory bowel disease before proceeding with interventions; as symptoms persist in many patients despite treatment [27].

There remains no consensus regarding the surgical management of giant hemangiomas, especially those with a size $>10 \mathrm{~cm}$ [8]. Some authors have claimed that size should not be an absolute indication for surgery, as a study done by Terkivaten et al. reported symptoms in 12 patients with hemangiomas $>4 \mathrm{~cm}$ either 
diminished or became minimal during follow-up [28]. However it is notable that the largest hemangioma treated conservatively during this study was $11 \mathrm{~cm}$. Other author's advocate for prophylactic treatment of asymptomatic hemangiomas $>10 \mathrm{~cm}$, as they pose a greater risk of hemorrhage, growth, or rupture. In a recent study by Mocchegiani et al., rupture occurred in 5/157 patients $(3.2 \%)$ with a hemangioma $>4 \mathrm{~cm}$ [11]. These results highlight the risks associated with conservative treatment of larger hemangiomas. Two common procedures for surgical intervention include enucleation and resection. Until recently, authors reported that enucleation was associated with decreased morbidity, intraoperative bleeding, hospital stay, and operative times [29-32]. Nevertheless, these studies included few patients with hemangiomas $>10 \mathrm{~cm}$. A more recent study in 2015 by Zhang et al. investigating 86 patients with giant hemangiomas $>10 \mathrm{~cm}$ treated with either enucleation or resection reported similar blood loss, blood product usage, operative time, hepatic vascular occlusion time and frequency, and complications between the two procedures [25]. These finding were in agreement with a similar study by Ulas et al. [33]. Enucleation remains a useful treatment option for both peripherally and centrally located hemangiomas, but with central hemangiomas the procedure was associated with significantly longer vascular inflow occlusion time, increased operating time, and more blood transfusion [25]. For this reason, surgical resection remains an attractive option if the hemangioma is deeply located in the liver parenchyma, occupies an entire lobe, or does not have a free surface from Glisson's capsule [13]. Trans-arterial embolization has been proposed as a treatment option in giant symptomatic hemangiomas, both alone and in combination with resection [15-22]. In a study of 98 patients with a hemangioma $>5 \mathrm{~cm}$, TAE monotherapy resulted in resolution of pain and distension in $87 \%$ of patients with baseline symptoms, with partial reduction in the other 13\% [22]. The diameter of the hemangiomas also decreased from a mean of $9.7 \mathrm{~cm}$ to $3 \mathrm{~cm}$. These results were compatible with study by Firouznia et al. [18]. Risks associated with TAE include pain, inoperability, non-target embolization, bile duct injury, pyrexia, leukocytosis, and nausea [15, 19, 34, 35]. When performed before surgical resection, TAE can improve hepatic mobility and reduce intraoperative blood loss $[19,20,23]$. Due to the risks associated with TAE and a possible inflammation in the portal triad, some authors advocate for surgical resection either on the same day or within days of the embolization [19, 21, 34]. Conversely, Zhou et al. argue that the timing of surgery should be based on close follow-up with the surgeon and interval imaging, ensuring that the hemangioma has decreased in size [23].

In our case, TAE followed by surgical resection the following day was determined to be the best treatment option after discussion with a multidisciplinary board. The hemangioma decreased in size from $22 \mathrm{~cm}$ to $16 \mathrm{~cm}$, greatly facilitating the mobilization of the right liver, which would have been quite challenging without that degree of shrinkage. There were no complications following TAE such as pain or pyrexia. Furthermore, there was only mild blood loss for a hemangioma of this size. Our outcomes are consistent with those from Vassiou et al., Bailey et al., and Kayan et al, who performed a similar technique with minimal blood loss, improved mobilization, and without inflow vascular occlusion [19-21]. Our quantified blood loss was also similar to the $400 \mathrm{~mL}$ reported by Zhou et al, who also reported a much longer post-operative stay than our patient (16 days vs. 7 days) [23]. We believe that TAE alone would not be an appropriate treatment option for this patient due to the side effects of TAE monotherapy, risk of future hemangioma complications, and insufficient evidence the patient's symptoms would resolve.

\section{Conclusion}

Based on our experience we believe that hemangiomas greater than $20 \mathrm{~cm}$ pose a significantly greater set of complexities regarding resection pertaining to blood loss and proper exposure and deserve of a sub classification we would term "Super Hemangiomas" and should be approached with TAE first followed by resection.

\section{References}

1. Brouwers MA, Peeters PM, de Jong KP, Haagsma EB, Klompmaker IJ, Bijleveld CM, et al. Surgical treatment of giant haemangioma of the liver. Br J Surg. 1997;84(3):314-316.

2. Gibney RG, Hendin AP, Cooperberg PL. Sonographically detected hepatic hemangiomas: absence of change over time. AJR Am J Roentgenol. 1987;149(5):953-957.

3. Rungsinaporn K, Phaisakamas T. Frequency of abnormalities detected by upper abdominal ultrasound. J Med Assoc Thai. 2008;91(7):10721075.

4. Adam YG, Huvos AG, Fortner JG. Giant hemangiomas of the liver. Ann Surg. 1970;172(2):239-245.

5. Berliner L, el Ferzli G, Gianvito L, Worth MH Jr, Lowry J, Redmond P, et al. Giant cavernous hemangioma of the liver complicated by abscess and thrombosis. Am J Gastroenterol. 1983;78(12):835-840.

6. Kawarada Y, Mizumoto R. Surgical treatment of giant hemangioma of the liver. Am J Surg. 1984;148(2):287-291.

7. Yoon SS, Charny CK, Fong Y, Jarnagin WR, Schwartz LH, Blumgart LH, et al. Diagnosis, management, and outcomes of 115 patients with hepatic hemangioma. J Am Coll Surg. 2003;197(3):392-402.

8. Schnelldorfer T, Ware AL, Smoot R, Schleck CD, Harmsen WS, Nagorney DM. Management of giant hemangioma of the liver: resection versus observation. J Am Coll Surg. 2010;211(6):724-730. doi: 10.1016/j. jamcollsurg.2010.08.006

9. Grieco MB, Miscall BG. Giant hemangiomas of the liver. Surg Gynecol Obstet. 1978;147(5):783-787.

10. van Tilborg AA, Nielsen K, Scheffer HJ, van den Tol P, van Waesberghe JH, Sietses $\mathrm{C}$, et al. Bipolar radiofrequency ablation for symptomatic giant $(>10 \mathrm{~cm})$ hepatic cavernous haemangiomas: initial clinical experience. Clin Radiol. 2013;68(1):e9-e14. doi: 10.1016/j.crad.2012.08.029

11. Mocchegiani F, Vincenzi P, Coletta M, Agostini A, Marzioni M, Baroni GS, et al. Prevalence and clinical outcome of hepatic haemangioma with specific reference to the risk of rupture: A large retrospective crosssectional study. Dig Liver Dis. 2016;48(3):309-314. doi: 10.1016/j. dld.2015.09.016 
12. Tait N, Richardson AJ, Muguti G, Little JM. Hepatic cavernous haemangioma: a 10 year review. Aust N Z J Surg. 1992;62(7):521-524.

13. Toro A, Mahfouz AE, Ardiri A, Malaguarnera M, Malaguarnera G, Loria $\mathrm{F}$, et al. What is changing in indications and treatment of hepatic hemangiomas. A review. Ann Hepatol. 2014;13(4):327-339.

14. Marrero JA, Ahn J, Rajender Reddy K, Americal College of G. ACG clinical guideline: the diagnosis and management of focal liver lesions. Am J Gastroenterol. 2014;109(9):1328-1347. doi: 10.1038/ajg.2014.213

15. Srivastava DN, Gandhi D, Seith A, Pande GK, Sahni P. Transcatheter arterial embolization in the treatment of symptomatic cavernous hemangiomas of the liver: a prospective study. Abdom Imaging 2001;26(5):510-514

16. Deutsch GS, Yeh KA, Bates WB 3rd, Tannehill WB. Embolization for management of hepatic hemangiomas. Am Surg. 2001;67(2):159-164

17.Granov AM, Tarazov PG, Polysalov VN. Arterial embolization in treatment of hepatic cavernous hemangioma. Khirurgiia (Mosk) 1999(4):13-17.

18. Firouznia K, Ghanaati H, Alavian SM, Nassiri Toosi M, Ebrahimi Daryani $\mathrm{N}$, Jalali $\mathrm{AH}$, et al. Management of liver hemangioma using transcatheter arterial embolization. Hepat Mon. 2014;14(12):e25788. Doi: 10.5812/hepatmon.25788

19. Vassiou K, Rountas H, Liakou P, Arvanitis D, Fezoulidis I, Tepetes K. Embolization of a giant hepatic hemangioma prior to urgent liver resection. Case report and review of the literature. Cardiovasc Intervent Radiol. 2007;30(4):800-802.

20. Kayan M, Cetin M, Aktas AR, Yilmaz 0, Ceylan E, Eroglu HE. Preoperative arterial embolization of symptomatic giant hemangioma of the liver. Prague Med Rep. 2012;113(2):166-171.

21. Bailey J, Di Carlo S, Blackwell J, Gomez D. Same day arterial embolisation followed by hepatic resection for treatment of giant haemangioma BMJ Case Rep. 2016. doi:10.1136/bcr-2015-213259

22.Zeng Q, Li Y, Chen Y, Ouyang Y, He X, Zhang H. Gigantic cavernous hemangioma of the liver treated by intra-arterial embolization with pingyangmycin-lipiodol emulsion: a multi-center study. Cardiovasc Intervent Radiol. 2004;27(5):481-485.

23. Zhou JX, Huang JW, Wu H, Zeng Y. Successful liver resection in a giant hemangioma with intestinal obstruction after embolization. World J Gastroenterol. 2013;19(19):2974-2978. doi: 10.3748/wjg.v19. i19.2974
24. Shaked O, Siegelman ES, Olthoff K, Reddy KR. Biologic and clinical features of benign solid and cystic lesions of the liver. Clin Gastroenterol Hepatol. 2011;9(7):547-62 e1-4. doi: 10.1016/j.cgh.2011.03.007

25.Zhang W, Huang ZY, Ke CS, Wu C, Zhang ZW, Zhang BX, et al. Surgical Treatment of Giant Liver Hemangioma Larger Than $10 \mathrm{~cm}$ : A Single Center's Experience With 86 Patients. Medicine (Baltimore) 2015;94(34):e1420. doi: 10.1097/MD.0000000000001420

26.Etemadi A, Golozar A, Ghassabian A, Zarei M, Hashemi Taheri AP, Dawsey SM, et al. Cavernous hemangioma of the liver: factors affecting disease progression in general hepatology practice. Eur J Gastroenterol Hepatol. 2011;23(4):354-358. doi: 10.1097/MEG.0b013e3283451e7d

27. Herman P, Costa ML, Machado MA, Pugliese V, D’Albuquerque LA, Machado MC, et al. Management of hepatic hemangiomas: a 14-year experience. J Gastrointest Surg. 2005;9(6):853-859.

28. Terkivatan T, Vrijland WW, Den Hoed PT, De Man RA, Hussain SM, Tilanus HW, et al. Size of lesion is not a criterion for resection during management of giant liver haemangioma. Br J Surg. 2002;89(10):12401244.

29. Kuo PC, Lewis WD, Jenkins RL. Treatment of giant hemangiomas of the liver by enucleation. J Am Coll Surg. 1994;178(1):49-53.

30. Gedaly R, Pomposelli JJ, Pomfret EA, Lewis WD, Jenkins RL. Cavernous hemangioma of the liver: anatomic resection vs. enucleation. Arch Surg. 1999;134(4):407-411.

31. Hamaloglu E, Altun H, Ozdemir A, Ozenc A. Giant liver hemangioma: therapy by enucleation or liver resection. World J Surg. 2005;29(7):890893.

32. Singh RK, Kapoor S, Sahni P, Chattopadhyay TK. Giant haemangioma of the liver: is enucleation better than resection? Ann R Coll Surg Engl. 2007;89(5):490-493. Doi: 10.1308/003588407X202038

33. Ulas M, Ozer I, Bostancil EB, Karaman K, Dalgic T, Polatl E, et al. Giant hemangiomas: effects of size and type of surgical procedure on postoperative outcome. Hepatogastroenterology. 2014;61(133):12971301.

34. Seo HI, Jo HJ, Sim MS, Kim S. Right trisegmentectomy with thoracoabdominal approach after transarterial embolization for giant hepatic hemangioma. World J Gastroenterol. 2009;15(27):3437-3439.

35. Huang XQ, Huang ZQ, Duan WD, Zhou NX, Feng YQ. Severe biliary complications after hepatic artery embolization. World J Gastroenterol. 2002;8(1):119-123. 